\title{
COUPLED SHEAR STRAIN-PORE PRESSURE RESPONSES OF SOIL IN SHAKING TABLE TESTS
}

\author{
Wen-Jong Chang ${ }^{\text {i)}}$, Tzou-Shin Ueng ${ }^{\text {ii) }}$, Chia-Han Chen ${ }^{\text {iii) }}$ and Chih-Wei Yang ${ }^{\text {iv) }}$
}

\begin{abstract}
Shaking table tests on a saturated sand specimen in a laminar shear box were performed to measure the coupled shear strain-pore pressure response of sands subjected to horizontal shaking. Three methods of shear strain evaluation techniques, which use soil motions recorded by embedded sensors within the soil specimen and external sensors on frame, were utilized to evaluate the shear strain-time histories in one-dimensional shaking cases. Coupled shear strainpore pressure responses throughout the liquefaction process are presented based on evaluated shear strains and measured pore pressures at corresponding depths. More insights of the interactions between the induced shear strain and generated excess pore pressure are also given, including the temporal variations of induced shear strain prior and after the initial liquefaction, development of liquefied zone, and duration of liquefaction state. These spatial and temporal variations of coupled responses reveal that the induced shear strain amplitude is not only an important property in triggering soil liquefaction but also a better index in defining the time of initial liquefaction. Identifications of these coupled features will be beneficial for verifying and interpreting testing data in physical modelling for liquefaction studies.
\end{abstract}

Key words: laminar shear box, liquefaction, pore pressure, shaking table test, shear strain evaluation (IGC: D7/E7)

\section{INTRODUCTION}

Soil liquefaction is a coupled behaviour between the induced shear strain and the accumulated excess pore pressure (Dobry et al., 1982). In a soil deposit, shear strains are generally induced from the passages of upward propagating shear stress waves. As a result, excess pore water pressures are generated from the induced shear strains. The generated excess pore pressure reduces the shear modulus of soil, which in turn alters the soil response under the shear stress waves. That is, a coupled interaction occurs between the induced shear strains and generated pore pressures in liquefaction process.

Using a large soil specimen on a shaking table to physically model seismic responses of soils has been an important testing method in the field of Geotechnical Earthquake Engineering (e.g., Koga and Matsuo, 1990). Laminar shear boxes on a shaking table have been used to contain soil specimens for simulating the free-field responses of soil deposits. Advantages of using large specimens include fewer boundary effects, more accurate representation of the field stress conditions prior and during the seismic loading, feasibility to measure responses at different locations, and less disturbance from the installed instruments (Rathje et al., 2005; Ueng et al., 2006). These features can be crucial in liquefaction study.
Due to the coupling features and effects from surrounding soils, simultaneous measurements of the induced shear strain and the accumulated excess pore pressure at a given location are necessary for studying liquefaction mechanism. In the current practice of liquefaction tests on shaking table, pore pressures and soil motions are measured at different locations, which may not accurately capture the coupled responses due to temporal and spatial variations of ground responses. Additionally, shear strain evaluation techniques using soil motion data have been proposed to obtain shear strain time histories of soil due to cyclic shearing (e.g., Chang, 2002). The applicability and accuracy of implementing these techniques in shaking table tests with significant pore pressure accumulation needs to be verified.

To minimize measurement errors due to temporal and spatial variations of ground responses, coupled sensors, which integrate a motion sensor and a miniature pore pressure transducer in a small case, and associated data reduction procedures were developed to study the coupled shear strain-pore pressure behaviour of a sand element at a given location subjected to horizontal shakings. Results from clean sand specimen contained in a bi-directional laminar shear box on the shaking table at the National Center for Research on Earthquake Engineering (NCREE) in Taiwan are analyzed and presented. This

i) Assistant Professor, Department of Civil Engineering, National Cheng Kung University, Taiwan (wjchang@mail.ncku.edu.tw).

ii) Professor Emeritus, Department of Civil Engineering, National Taiwan University, Taiwan.

ii) PhD Student, ditto.

iv) Formerly Graduate Student, Graduate Institute of Earthquake and Disaster Mitigation Engineering, National Chi Nan University, Taiwan. The manuscript for this paper was received for review on January 14, 2009; approved on December 2, 2009.

Written discussions on this paper should be submitted before November 1, 2010 to the Japanese Geotechnical Society, 4-38-2, Sengoku, Bunkyo-ku, Tokyo 112-0011, Japan. Upon request the closing date may be extended one month. 
paper presents the framework of the instrumentation system, data reduction procedures, and testing results of a clean sand subjected to one-directional sinusoidal shaking. Comparisons of shear strains evaluated by three techniques are conducted to examine the adequateness of these techniques. The evaluated shear strains and corresponding pore pressures from liquefied and non-liquefied zones are presented and the coupled shear strain-pore pressure responses are discussed. These efforts aim to investigate temporal and spatial variations of coupled shear strain-pore pressure response during liquefaction process. The results will be beneficial for verifying and interpreting testing data in physical modelling for liquefaction studies.

\section{TESTING FACILITIES AND TESTING PROGRAM}

\section{Laminar Shear Box}

The laminar shear box used in this study was developed at NCREE and was placed on the multidirectional shaking table $(5 \mathrm{~m} \times 5 \mathrm{~m})$ at the same institute. The laminar shear box consists of 15 layers of light aluminium alloy frames with a specimen size of 1.88 by 1.88 by $1.52 \mathrm{~m}$ in length, width, and height, respectively. Each layer is composed of two nested frames supported independently on the outside rigid wall. Each frame is $80 \mathrm{~mm}$ in height with a $20-\mathrm{mm}$ gap between layers except the top frame, which is $100 \mathrm{~mm}$ high. Key features of the NCREE laminar shear box include: (1) capability of bi-directional shaking on the horizontal plane without torsional motion, (2) no accumulation of both frictional and inertial effects of frames, and (3) tolerance of large relative motions between layers (Ueng et al., 2006).

Accelerometers and pore pressure transducers (piezometers) were embedded separately in the soil specimen to monitor respectively the soil motions and pore pressure changes during shaking tests. The configuration of the internal instrumentation is shown in Fig. 1(a). Miniature accelerometers $(\mathrm{PCB} 1 \sim 4)$ were evenly placed at a vertical axis of the specimen to measure the horizontal accelerations at different depths. Pore pressure transducers (wp1 15) were installed at different depths at locations as shown in Fig. 1(a) and were used to detect temporal and spatial variations of pore pressures. These internal sensors were fixed at the designated locations with proper orientations by fishing lines before sand pluviation. The fishing lines were cut to release constrains prior to the shaking test.

Outside the specimen, magnetostriction-type linear displacement transducers (LDTs) and accelerometers were used to measure the horizontal displacements and accelerations of each frame as shown in Fig. 1(b). The dense instrumentations deployed inside the soil specimen and on the model container provide data for study of temporal and spatial variations of soil responses during the liquefaction process. In addition, cross comparisons of different shear strain evaluation methods can be conducted using the measurements by these conventional sensors.

\section{Coupled Sensor}

To monitor local ground motions and pore pressure changes simultaneously, the "coupled sensor" was fabricated by integrating a triaxial, low-frequency accelerometer and a miniature pore pressure transducer in a cylindrical, acrylic case of a size of $55 \mathrm{~mm}$ in diameter and $78 \mathrm{~mm}$ in length. An acrylic case was machined to provide a waterproof enclosure for the accelerometer and enable the necessary wire connections. Important features of coupled sensors include: (1) the small size for simultaneously measuring both the soil acceleration and pore pressure at almost the same location, (2) the low-frequency band (DC to $100 \mathrm{~Hz}$ in $95 \%$ accuracy) and triaxial components for capturing motion characteristics of real earthquakes, and (3) the design of the flexible and bended cable for less cable interference.

Four coupled sensors, CS-1, CS-2, CS-3, and CS-4, were deployed to form a $0.6 \mathrm{~m}$ by $0.6 \mathrm{~m}$ square array on a

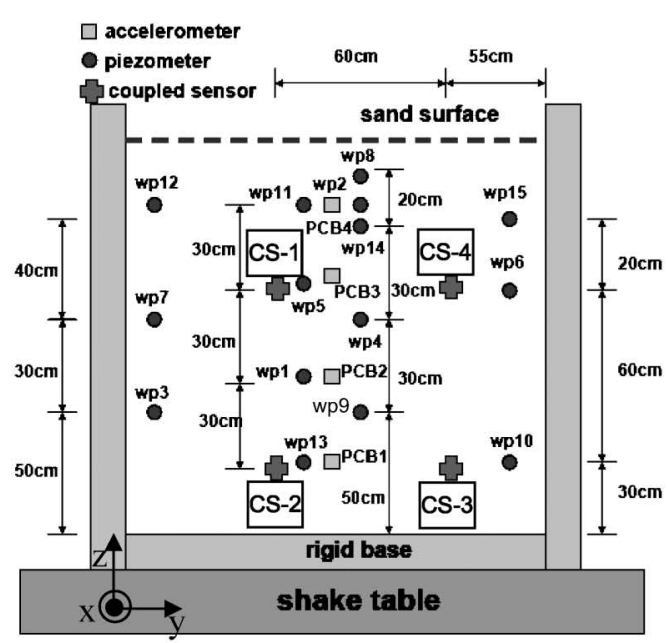

(a)

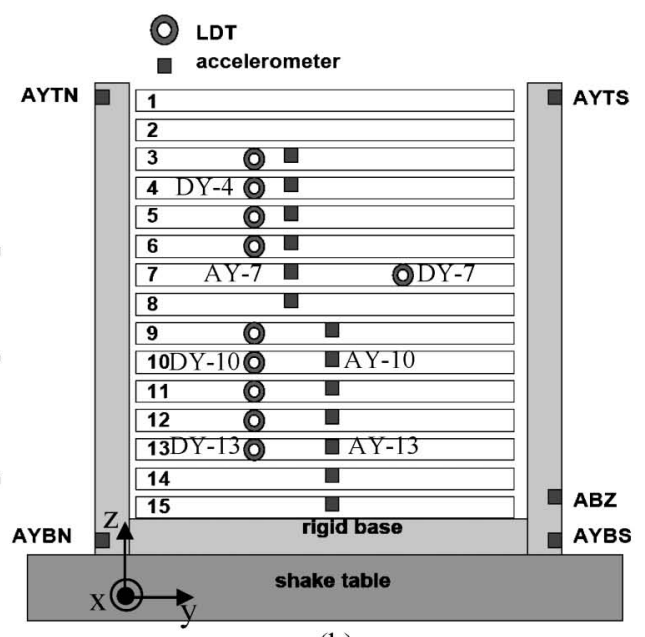

(b)

Fig. 1. Layouts of internal and external instrumentation systems (not to scale): (a) internal and (b) external 
vertical plane parallel to the wave propagation direction as shown in Fig. 1(a). The four coupled sensors of the square array provided measurements for calculations of the shear strain within the array using various strain calculation techniques described in the next section. For each coupled sensor, the three axes of the accelerometer were oriented to parallel with the three coordinate directions (x, y, and $\mathrm{z}$ in Fig. 1) of the laminar shear box. To verify the orientation and perform tilt correction, the accelerations of coupled sensors were compared with the horizontal frame accelerations at the same depth under a very small shaking level.

\section{Testing Material and Sample Preparation}

The testing soil is a clean, fine silica sand imported from Vietnam, which had been used in various liquefaction studies in Taiwan (e.g., Ueng et al., 2006; Chang and Hong, 2008) for its consistent gradation and easy purchasing. The Vietnam sand is white in colour with a specific gravity of 2.65 , maximum void ratio of 0.92 , and minimum void ratio of 0.61 . The Vietnam sand is classified as poorly graded sand (SP) in the Unified Soil Classification System (USCS).

Saturated specimens were prepared in a water sedimentation fashion with a pluviator hanging above the laminar shear box. After the pluviation process, the specimen was fully submerged for at least 3 days to achieve a fully saturation of the soil and the filter of piezometer. The sample preparation procedure used in this study had been verified to produce a saturated, uniform specimen with initial dry density ranging from $1440 \mathrm{~kg} / \mathrm{m}^{3}$ to $1490 \mathrm{~kg} / \mathrm{m}^{3}$, depending on the rate of pluviation (Ueng et al., 2006). The amplitude and phase characteristics in pore pressure time histories recorded by piezometers showed that the filter of piezometer was fully saturated. According to the travel time of the two coupled sensors CS-1 and CS-2, the average shear wave velocity of the $60 \mathrm{~cm}$ thick soil was 46 $\mathrm{m} / \mathrm{s}$, which corresponded to an overburden-stress corrected velocity $\left(V_{\mathrm{s} 1}\right)$ of $91 \mathrm{~m} / \mathrm{s}$ and the cyclic resistance ratio less than 0.1 (Andrus and Stokoe, 2000).

\section{Testing Sequence}

Limited by the access time of the shaking table and cost of testing, a special testing program was performed to study the shaking induced liquefaction on a clean sand specimen. A total of 32 shaking tests were performed with acceleration amplitudes from 0.01 to $0.2 \mathrm{~g}$, loading frequencies of 1 to $8 \mathrm{~Hz}$, and durations of 20 to 32 cycles. The testing program started from a small, sinusoidal shaking in y-direction with acceleration amplitude of 0.01 $\mathrm{g}$ at a frequency of $1 \mathrm{~Hz}$ for $20 \mathrm{~s}$. This small sinusoidal shaking was used for system check of the entire system, including the performance of shaking table, integrity of instrumentation, specimen characterization, and cross verification between the embedded and external instrumentation systems. To ensure the proper orientations of the embedded motion sensors, this small shaking was repeated after tests with significant excess pore pressure generation.

\section{DATA REDUCTION}

In this study, the laminar shear box and the shaking table are used to model upward propagating shear waves with particle motions in the horizontal plane. Limited by the number of coupled sensors, only the results of onedimensional horizontal shaking are discussed. The recorded soil accelerations, pore pressures, frame accelerations, and frame displacements were processed to compute time histories of induced shear strains and excess pore pressure ratios at various locations. Coupled responses of the shear strain and pore pressure were observed at the same location. Three shear strain evaluation techniques are implemented to evaluate shear strains at different locations. Summary of the three methods is tabulated in Table 1 and detailed descriptions are provided below.

\section{Data Reduction Procedure}

The procedure of data reduction is shown in Fig. 2. Background noises of raw data were filtered out by a lowpassing filter with $40 \mathrm{~Hz}$ cut off frequency. The frame accelerations were used for cross verifications with the embedded motion sensors and frame movements were used

Table 1. Summary of shear strain evaluation methods

\begin{tabular}{|c|c|c|c|}
\hline $\begin{array}{l}\text { Method } \\
\text { (acronym) }\end{array}$ & $\begin{array}{l}\text { Fundamental } \\
\text { relationship }\end{array}$ & $\begin{array}{l}\text { Measured } \\
\text { properties }\end{array}$ & $\begin{array}{l}\text { Calculated } \\
\text { properties }\end{array}$ \\
\hline $\begin{array}{l}\text { 2D displacement- } \\
\text { based method } \\
(2 \mathrm{DBM})\end{array}$ & Equation (1) & $\begin{array}{c}\text { Nodal } \\
\text { displacements at } \\
4 \text { nodal points }\end{array}$ & $\begin{array}{l}\text { Strain components } \\
\text { at point inside } \\
\text { array }\end{array}$ \\
\hline $\begin{array}{l}\text { 1D displacement- } \\
\text { based method } \\
\text { (1DBM) }\end{array}$ & Equation (3) & $\begin{array}{c}\text { Horizontal } \\
\text { displacements at } \\
2 \text { internal points }\end{array}$ & $\begin{array}{c}\text { Average shear } \\
\text { strain between two } \\
\text { elevations }\end{array}$ \\
\hline $\begin{array}{l}\text { Frame shear } \\
\text { beam method } \\
\text { (FSBM) }\end{array}$ & Equation (2) & $\begin{array}{l}\text { Horizontal } \\
\text { displacements of } \\
2 \text { frames }\end{array}$ & $\begin{array}{c}\text { Average shear } \\
\text { strain between two } \\
\text { frames }\end{array}$ \\
\hline
\end{tabular}

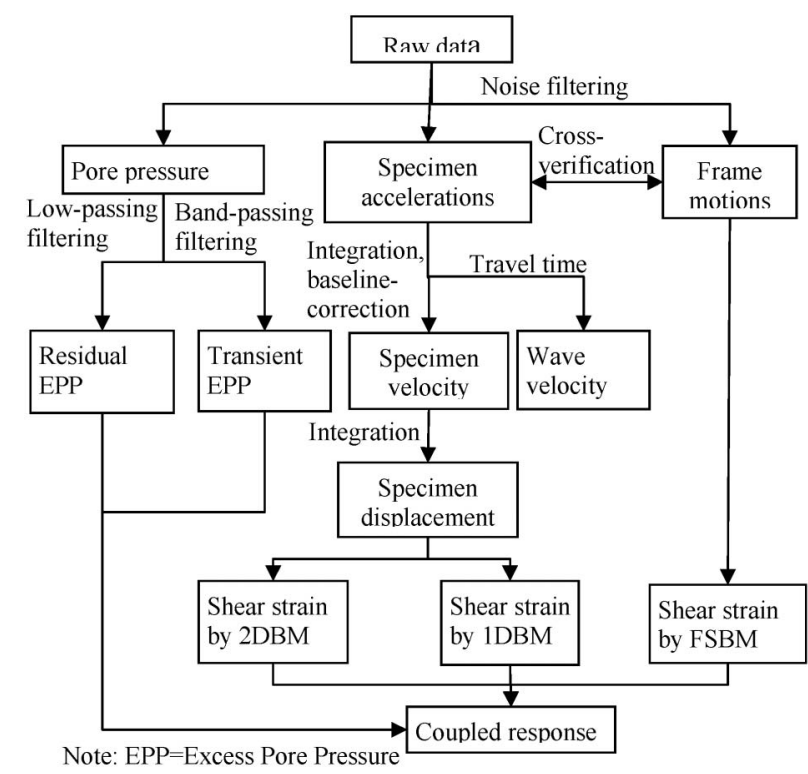

Fig. 2. Procedure of data reduction 
to calculate shear strain. The acceleration-time histories from embedded and frame accelerometers were numerically integrated to obtain the velocity-time histories. In addition, the acceleration-time histories at different depths were used to determine the wave propagation velocity from the travel time of shear waves between two accelerometers. To remove the shifting in a velocity-time history due to noises and initial offsets in the acceleration records, a baseline correction using high order polynomial was conducted on velocity-time histories to ensure a zero-velocity after shaking. Corrected velocity-time histories were integrated again to obtain displacementtime histories that were used in evaluating shear strains by displacement-based methods. To verify the accuracy of the displacements from double integration of acceleration records, displacement-time histories from frame accelerometers are compared with the corresponding frame movements measured directly with LDTs.

The recorded pore pressures contain three components: (1) the hydrostatic pore pressure remaining constant during the test, (2) the transient excess pore pressure oscillating with the dynamic loading, and (3) the residual pore pressure representing the net outcome of accumulation and dissipation of the excess pore pressure. To focus on the excess pore pressures, hydrostatic pore pressures were subtracted from the records. To highlight and analyze the residual and transient excess pore pressures separately, low-passing and band-passing filters are used respectively. A low-passing filter removes components with frequencies above $2 \mathrm{~Hz}$. A band-passing filter removes components with frequencies outside the frequency range from $2 \mathrm{~Hz}$ to $12 \mathrm{~Hz}$. Combining the computed shear strain at the location of pore pressure measurement, the coupled response of the shear strain and the excess pore pressure was evaluated.

\section{Shear Strain Evaluation}

Three shear strain evaluation techniques were implemented to process shaking table data. The 2D displacement-based method (denoted as 2DBM) uses the same technology described in Rathje et al. (2005). Assuming that the size of the square element in Fig. 1(a) is $2 a$ in both $\mathrm{y}$ (horizontal) and $\mathrm{z}$ (vertical) directions and the origin $(y=0, z=0)$ of the element is at the center of the array, the coordinates of the four coupled sensors are $(-a, a),(-a,-a),(a,-a)$, and $(a, a)$ for CS-1, CS-2, CS-3, and CS-4 respectively. The shear strain of any point within the element with a coordinates of $y$ and $z$ is evaluated by:

$$
\begin{aligned}
\gamma_{\mathrm{yz}}(y, z)= & \frac{1}{4 a}\left[u_{\mathrm{y} 1}\left(1-\frac{y}{a}\right)-u_{\mathrm{z} 1}\left(1+\frac{z}{a}\right)-u_{\mathrm{y} 2}\left(1-\frac{y}{a}\right)\right. \\
& -u_{\mathrm{z} 2}\left(1-\frac{z}{a}\right)-u_{\mathrm{y} 3}\left(1+\frac{y}{a}\right)+u_{\mathrm{z} 3}\left(1-\frac{z}{a}\right) \\
& \left.+u_{\mathrm{y} 4}\left(1+\frac{y}{a}\right)+u_{\mathrm{z} 4}\left(1+\frac{z}{a}\right)\right]
\end{aligned}
$$

where $u_{\mathrm{ij}}$ is the displacement in the $i$ direction $(i=\mathrm{y}$ or $\mathrm{z})$ at node $j(j=1$ to 4$)$. The nodal displacement components are computed by double integration on the vertical and horizontal acceleration records.

The fundamental assumption employed in all three displacement-based strain evaluation techniques is the linear variation of displacement between nodes. To ensure that the computed shear strains are not significantly affected by nonlinear variation effects, the whole array must be in the same phase of state (i.e., liquefied or non-liquefied state) to avoid a sharp change of wave velocity and the distance between measured points should be restricted. Considering the first quarter wavelength of a sinusoidal waveform, a relatively constant slope exists except the 5 $\%$ wavelength near the peak. As a result, 1/5 wavelength of the minimum wavelength is recommended as the upper bound of the distance between measured points. In this study, the largest distance used in the data processing is $0.6 \mathrm{~m}$. For a specimen with shear wave velocity of $91 \mathrm{~m} / \mathrm{s}$ subjected to $8 \mathrm{~Hz}$ loading, the wavelength is $11.4 \mathrm{~m}$ and the distance between measured points is only 0.05 of the wavelength, which is far below $1 / 5$ wavelength.

In the one-dimensional shear wave propagation condition, a soil deposit can be approximately modelled as a stack of shear beams and the average shear strain $\left(\gamma_{12}\right)$ between two depths of $z_{1}$ and $z_{2}$ is defined as:

$$
\gamma_{12}=\frac{u_{\mathrm{y} 1}-u_{\mathrm{y} 2}}{\left(z_{2}-z_{1}\right)}
$$

where $u_{\mathrm{yi}}$ represents the horizontal displacement of point $i$ at the depth of $z_{\mathrm{i}}$. The numerator of Eq. (2) represents the relative horizontal displacement between two depths with the depth difference at the value of the denominator.

In the shaking table tests, the horizontal displacement at a specific depth can be measured from the frame motions or evaluated from the double integration of the horizontal acceleration measured by an embedded accelerometer. The shear beam method using the horizontal displacements evaluated by embedded measurements is named the 1D displacement-based method (denoted as 1DBM) and the one using the frame movements is named the frame shear beam method (denoted as FSBM). Differences between the two methods depend on the lateral variations of the soil motions. Comparisons between the 1DBM and FSBM were conducted in this study and the applicability of FSBM is presented later.

Equation (1) can be simplified to Eq. (2) for the shear beam conditions, that is, only the horizontal displacements are considered (i.e., $u_{\mathrm{zi}}=0$ for $i=1$ to 4 ) and the horizontal displacements at the same depth are the same (i.e., $u_{\mathrm{y} 1}=u_{\mathrm{y} 4}$ and $u_{\mathrm{y} 2}=u_{\mathrm{y} 3}$ ). Because all displacements in the $\mathrm{z}$-direction are zero, the vertical components have no effect on the evaluated shear strain. Accordingly, the average shear strain between CS-1 and CS-2 is:

$$
\gamma_{12}=\frac{u_{\mathrm{y} 1}-u_{\mathrm{y} 2}}{2 a}
$$

where $2 a$ is the depth difference between CS-1 and CS-2 and $u_{\mathrm{y} 1}$ and $u_{\mathrm{y} 2}$ are the horizontal displacements at CS-1 and CS-2, respectively. The shear strain evaluated by (3) is independent of the depth (i.e., z-coordinate) because of 
the linear variation assumption. For nonlinear variation cases, the strain by Eq. (3) represents the average shear strain between sensor CS-1 and CS-2.

\section{TESTING RESULT AND SHEAR STRAIN EVALUATION}

\section{Accelerations and Pore Pressures}

Before conducting further interpretations of the testing results, the spatial variations of the specimen responses need to be quantified and the performance of the model container needs to be calibrated as well. The time histories of accelerations, and pore pressures at a depth of 46 and $106 \mathrm{~cm}$ for case 20 are used to demonstrate the spatial variations of responses. The loading condition for case 20 is a sinusoidal motion in y-direction, with excitation amplitude of $0.1 \mathrm{~g}$ at a frequency of $8 \mathrm{~Hz}$ for $4 \mathrm{~s}$, which caused the upper part of the specimen to liquefy. Sensors PCB3, CS-1, and CS-4 were all located at the depth of $46 \mathrm{~cm}$ but away from the wall of the container at horizontal distances of 80,78 , and $55 \mathrm{~cm}$, respectively. Sensors PCB1, CS2, and CS3 were located at the depth of $106 \mathrm{~cm}$. Sensors AY-7 and AY-13 were the acceleration transducers on frame 7 and 13 respectively, which is at the same elevation as the two sets of embedded sensors, as shown in Fig. 1(b).

Comparisons of accelerations and excess pore pressures are shown in Figs. 3(a) and (b), respectively. The time of initial liquefaction (TI), defined as the excess pore pressure ratio $r_{\mathrm{u}}\left(r_{\mathrm{u}}=\Delta u / \sigma_{\mathrm{vi}}^{\prime} \Delta u=\right.$ accumulated excess pore pressure, $\sigma_{\mathrm{vi}}^{\prime}=$ initial effective vertical stress) reached 1.0 , at CS-1 is at $2.65 \mathrm{~s}$ as shown in Fig. 3(b). The horizontal accelerations of sensors at the depth of $46 \mathrm{~cm}$ agree well before the occurrence of initial liquefaction at CS-1. However, discrepancy occurred among the embedded sensors (CS-1, PCB3, and CS-4) and the frame acceleration (AY-7) after liquefaction, as shown in Fig. 3(a). Accelerations measured at the depth of $106 \mathrm{~cm}$, which remained non-liquefied throughout the shaking, also showed good agreement and a relatively constant amplitude was induced during the shaking. The high match of motion measured at the same depth before initial liquefaction indicates that the spatial variations of horizontal particle motions were very small in non-liquefied zone. The good agreements of motion measurements between the embedded and external instruments confirm
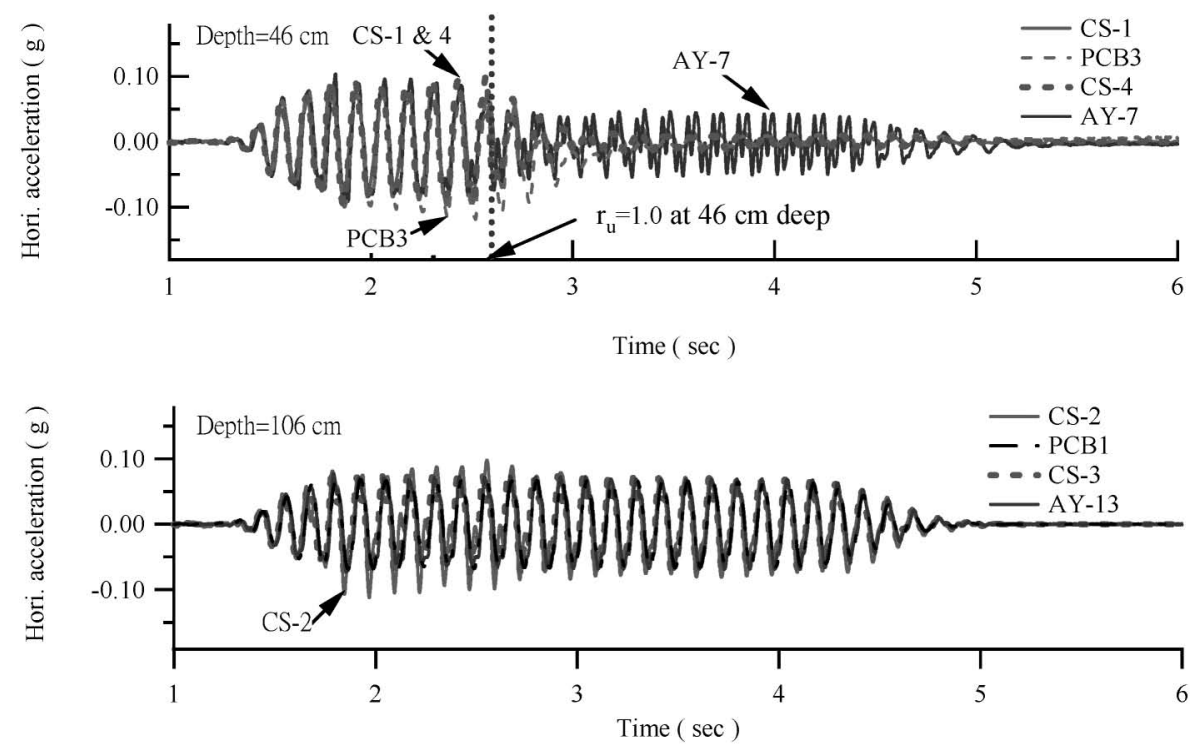

(a)

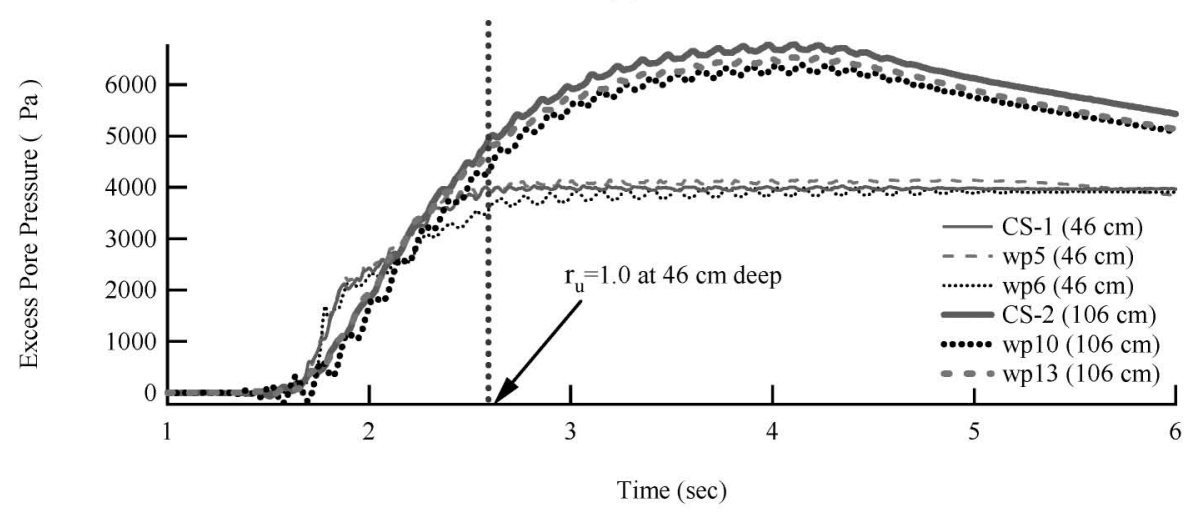

(b)

Fig. 3. Spatial variations of responses in a typical liquefied case: (a) acceleration and (b) excess pore pressure 


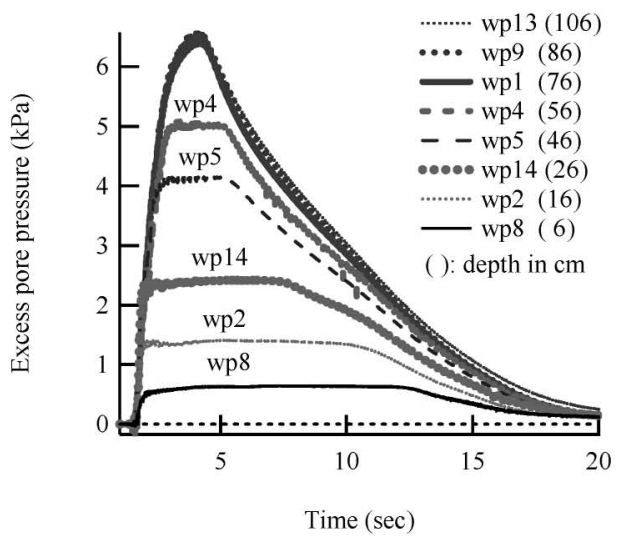

(a)

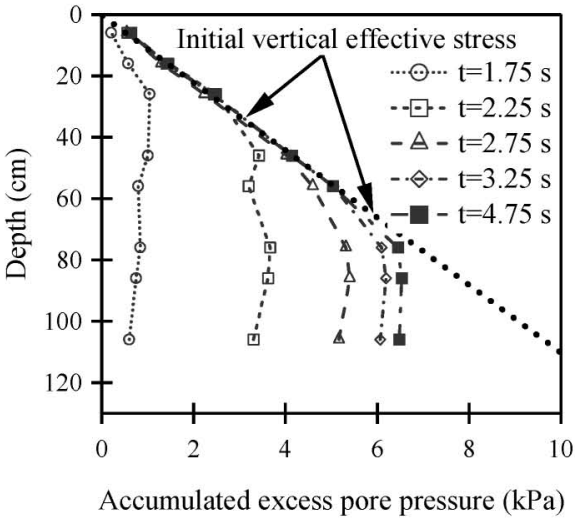

(b)

Fig. 4. Excess pore pressure variations for case 20: (a) time histories and (b) profiles of accumulated excess pore pressure

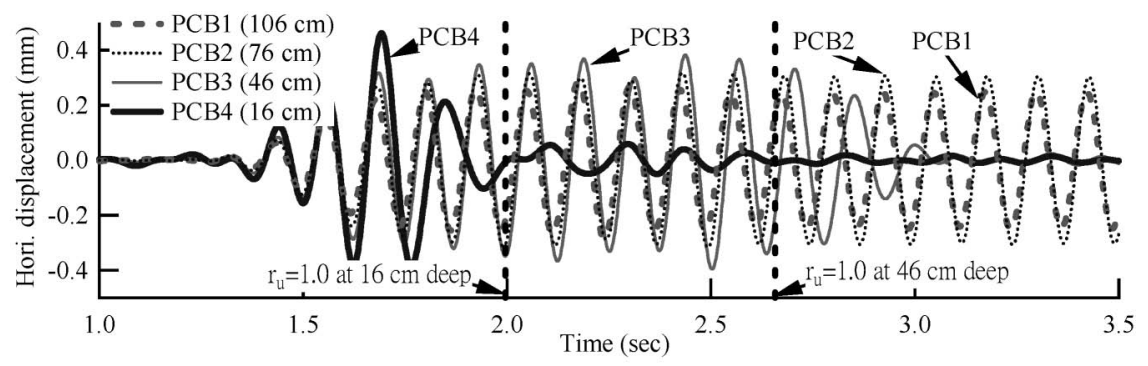

(a)

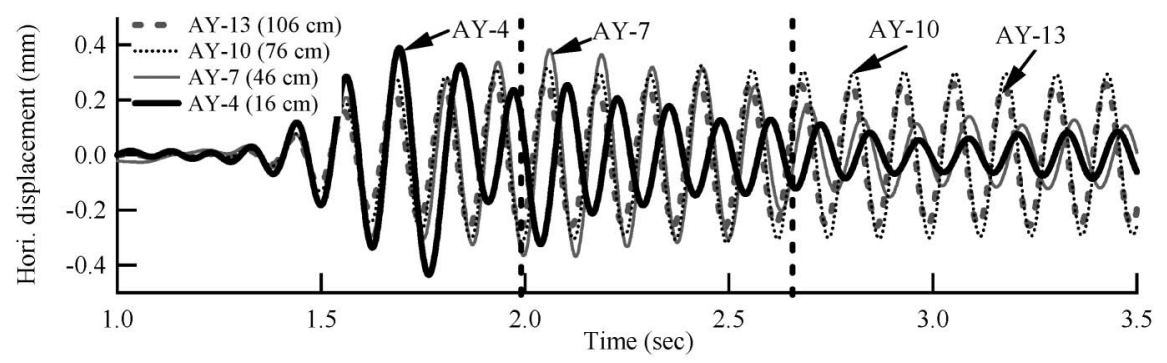

(b)

Fig. 5. Motion responses at liquefied and non-liquefied zones: (a) internal measurements and (b) frames measurements

the effectiveness of data reduction procedure and good performance of the NCREE laminar shear box.

The generated excess pore pressures at the depths of 46 $\mathrm{cm}$ (CS-1, wp5, and wp6) and $106 \mathrm{~cm}$ (CS-2, wp10, and wp13) are shown in Fig. 3(b). The initial vertical effective stresses at the depths of $46 \mathrm{~cm}$ and $106 \mathrm{~cm}$ are $4.0 \mathrm{kPa}$ and $9.0 \mathrm{kPa}$, respectively. The soil at the depth of $46 \mathrm{~cm}$ had liquefied; however, the soil at the depth of $106 \mathrm{~cm}$ did not liquefy $\left(r_{\mathrm{u}} \approx 0.7\right)$. In contrast to the significant spatial variations in motions, the excess pore pressure-time histories at the same depth agree well as shown in Fig. 3(b). The temporal and spatial variations of excess pore pressure are shown in Fig. 4. Figure 4(a) shows the time histories of excess pore pressures measured at different depths. Profiles of residual excess pore pressures at differ- ent times are shown in Fig. 4(b), along with the profile of the initial vertical effective stress. Figure 4 clearly shows that the liquefied zone only extended to about $80 \mathrm{~cm}$ deep throughout the shaking period, which indicates that sensors CS-2, and CS-3 were within the non-liquefied zone while sensors CS-1 and CS-4 were in the liquefied zone.

The occurrence of liquefaction had significantly altered the soil motions in the liquefied zone, as shown in Fig. 3(a). To further demonstrate the effects of altered ground motions on displacement responses between the liquefied and non-liquefied zones, the displacement responses calculated from the embedded accelerations measured by PCB1, PCB2, PCB3 and PCB4 and oscillatory frame movements at the corresponding elevations (frames 13, 10, 7, and 4) for case 20 are plotted in Figs. 5(a) and (b), 
respectively. Sensors PCB3 and PCB4 were within the liquefied zone, PCB1 was in the non-liquefied zone, and sensor PCB2 was at the proximity of the boundary between liquefied and non-liquefied zones. The initial liquefaction at depths of PCB4 and PCB3 occurred at $1.99 \mathrm{~s}$ and 2.65 $\mathrm{s}$ respectively according to pore pressure data from wp2 and wp5. Significant amplitude reduction and phase shift occurred after initial liquefaction as shown in Fig. 5(a). The frame displacements also showed reduction of amplitude and phase shift in liquefied layer (e.g., AY-4) as shown in Fig. 5(b). Comparisons between the internal and external measurements of the horizontal displacements in the liquefied zone show that both internal and external measurements behaved as free vibration decay after initial liquefaction and the internal motions at the corresponding depth decay much faster than the external motions.

\section{Shear Strain Time Histories}

The existence of different soil phases (i.e., liquefied and non-liquefied) raised concerns of implementing shear strain evaluation methods based on linear interpolations of motions; as a result, the suitability of shear strains evaluated by displacement-based methods using data from both liquefied and non-liquefied zones should be verified.

Shear strains evaluated by 2DBM with $(y, z)=(-a, 0)$ and 1DBM with data of coupled sensors CS-2 (non-liquefied) and CS-1 (liquefied) are plotted in Fig. 6(a) along with shear strain by FSBM with data of frames 13 (nonliquefied) and 7 (liquefied). The evaluated shear strain represented the average shear strain within depths of 46 to $106 \mathrm{~cm}$ and was a rational representation of the shear strain at the midpoint ( $76 \mathrm{~cm}$ deep) of the $60 \mathrm{~cm}$ thick soil. The average shear strains evaluated by 2DBM and 1DBM are almost identical throughout the shaking, which indicates that the vertical components of motion has little effect on the induced shear strain and confirmed that the soil was under shear beam mode. Because the data used to obtain the results in Fig. 6(a) included those in both the liquefied and non-liquefied zones, these calculated shear strains could be erroneous due to violation of linear displacement variations assumption.

To reduce the deviation from nonlinear displacement variation, two approaches had been adopted that included using the measurements all within the liquefied zone and shortening the elevation distance between measurements. Displacements from embedded sensors PCB3 and PCB4, which were all within the liquefied zones, were used in 1DBM to evaluate average shear strains of the 30 $\mathrm{cm}$ thick soil from depths of 16 to $46 \mathrm{~cm}$ with midpoint at $31 \mathrm{~cm}$ deep. Frame movements of AY-4 and AY-7 were used in FSBM to evaluate the average shear strain between depths of 11 to $51 \mathrm{~cm}$ and the result was a rational representation of the shear strain at the midpoint $(31 \mathrm{~cm}$ deep) of the $40 \mathrm{~cm}$ thick soil. To shorten the elevation difference, frame movements from two adjacent frames, AY-5 and AY-6, were used to evaluate shear strain of the soil within 21 to $41 \mathrm{~cm}$ deep and the result was also a rational representation of the average shear strain of the 20 $\mathrm{cm}$ thick soil with midpoint at a depth of $31 \mathrm{~cm}$. The three shear strain-time histories are shown in Fig. 6(b) along with times of initial liquefaction from piezometers at corresponding depths.

The shear strain waveforms between PCB3 and PCB4 evaluated from internal (1DBM) and frame measure-

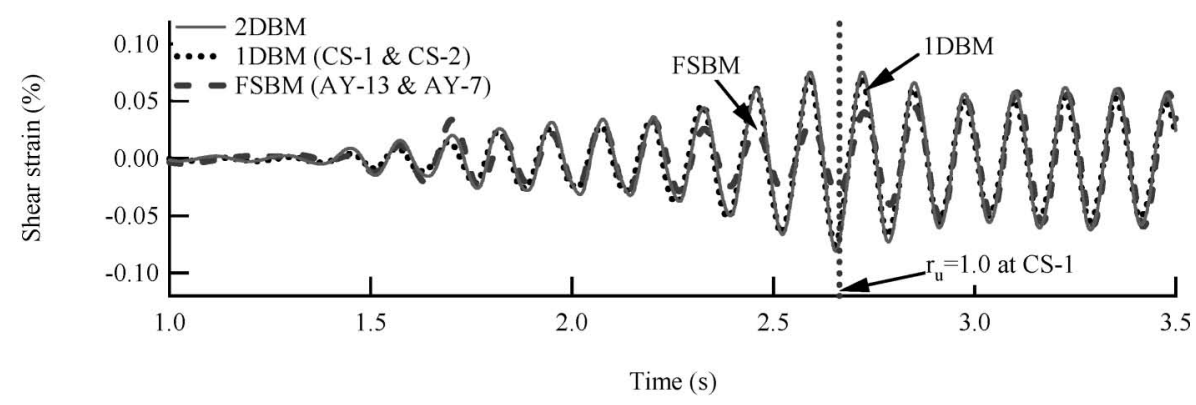

(a)

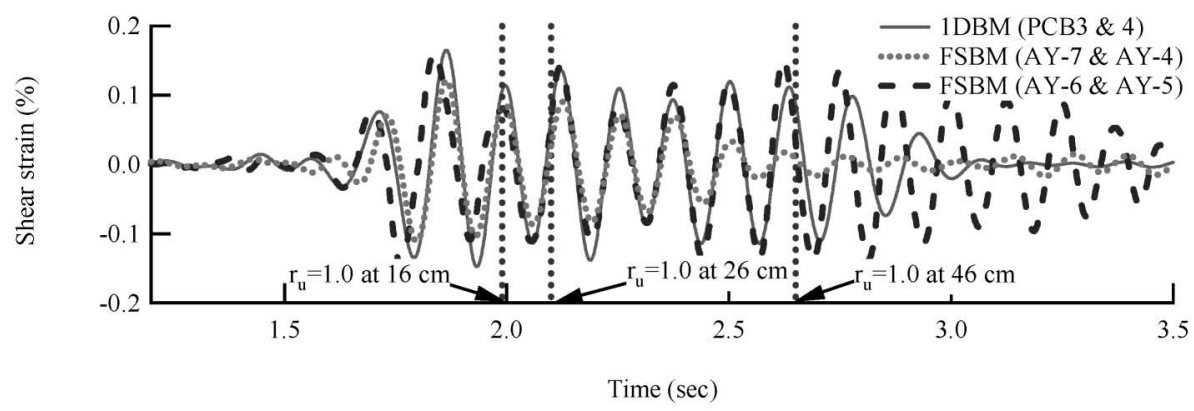

(b)

Fig. 6. Comparisons of average shear strain: (a) 46 to $106 \mathrm{~cm}$ deep and (b) 16 to $46 \mathrm{~cm}$ deep 
ments (FSBM) agreed well before the occurrence of initial liquefaction within the measurement zone $(t=0 \sim 1.99 \mathrm{~s})$ and the largest shear strain amplitude was induced at the time of initial liquefaction but the shear strain amplitude in FSBM was approximately $25 \%$ lower than that in 1DBM. The discrepancy increased after the initial liquefaction of the top sensor $(t=1.99 \sim 2.65 \mathrm{~s})$. Soon after the liquefied zone extending to the depth of PCB3 $(t>2.65 \mathrm{~s})$, the shear strain amplitudes evaluated by both 1DBM and FSBM decreased to very small values and significant phase difference was observed.

Before the liquefied zone reached the depth of PCB4 $(t<1.99 \mathrm{~s})$, the shear strain evaluated by FSBM with AY-5 and AY-6 showed slight phase difference from 1DBM due to different thickness of soil between measurement points, but the magnitude agreed better than FSBM with AY-4 and AY-7. From the time of 1.99 to $2.65 \mathrm{~s}$, FSBM with adjacent frames agreed well both in magnitude and phase but the magnitude by FSBM with AY-4 and AY-7 was smaller than 1DBM. Significant variations both in phase and amplitude between 1DBM and FSBM were observed after full liquefaction of the measured zone $(t>2.65 \mathrm{~s})$, which reflected the free vibration decay feature of frames in Fig. 5(b). Comparisons of two FSBM waveforms in Fig. 6(b) indicate that shear strain evaluation could be improved by reducing the elevation difference of two frames. Nevertheless, from the standpoint of induced shear strain amplitude, the shear strain by FSBM with relative displacement of adjacent frames could be an alternative approximation to embedded measurements in fully liquefied zone and is a rational representation of induced shear strain amplitude in liquefied soil until the lower frame was fully liquefied.

\section{COUPLED RESPONSE AND DISCUSSION}

\section{Temporal Coupled Response}

The coupled response at the location of coupled sensor CS-1 for case 20 is shown in Fig. 7. The shear strain at CS-1 was evaluated in two steps. First, to reduce the time lag and spatial variation effect, shear strain at CS-1 was evaluated by $2 \mathrm{DBM}$ with $(y, z)=(-a,-a)$ for Eq. (1) until the time that the liquefied zone extended to the depth of CS-1 $(t=2.65 \mathrm{~s})$. To reduce the effects of nonlinear variations between measured points, the shear strain after $2.65 \mathrm{~s}$ was evaluated by $1 \mathrm{DBM}$ with displacements calculated from CS-1 and PCB4, which were both in the liquefied zone.

The time histories of the horizontal acceleration, shear strain, and excess pore pressure ratio at the location of CS- 1 in case 20 are shown in Figs. 7(a), (b) and (c), respectively. In view of the variation of $r_{\mathrm{u}}$, the liquefaction process could be divided into different stages. In the first stage, significant excess pore pressure was generated and accumulated. The horizontal acceleration and shear strain amplitude increased due to reduction of shear modulus from increasing $r_{\mathrm{u}}$ and the maximum shear strain occurred at the time of initial liquefaction. The occurrence of maximum shear strain amplitude can be an alternative indication in finding the time of initial liquefaction.

In the second stage, the soil reached initial liquefaction and maintained the liquefied state until the end of shaking. In this stage, amplitudes of the horizontal acceleration and shear strain reduced in a free vibration fashion after the occurrence of initial liquefaction. The reduction of acceleration amplitude after initial liquefaction indi-

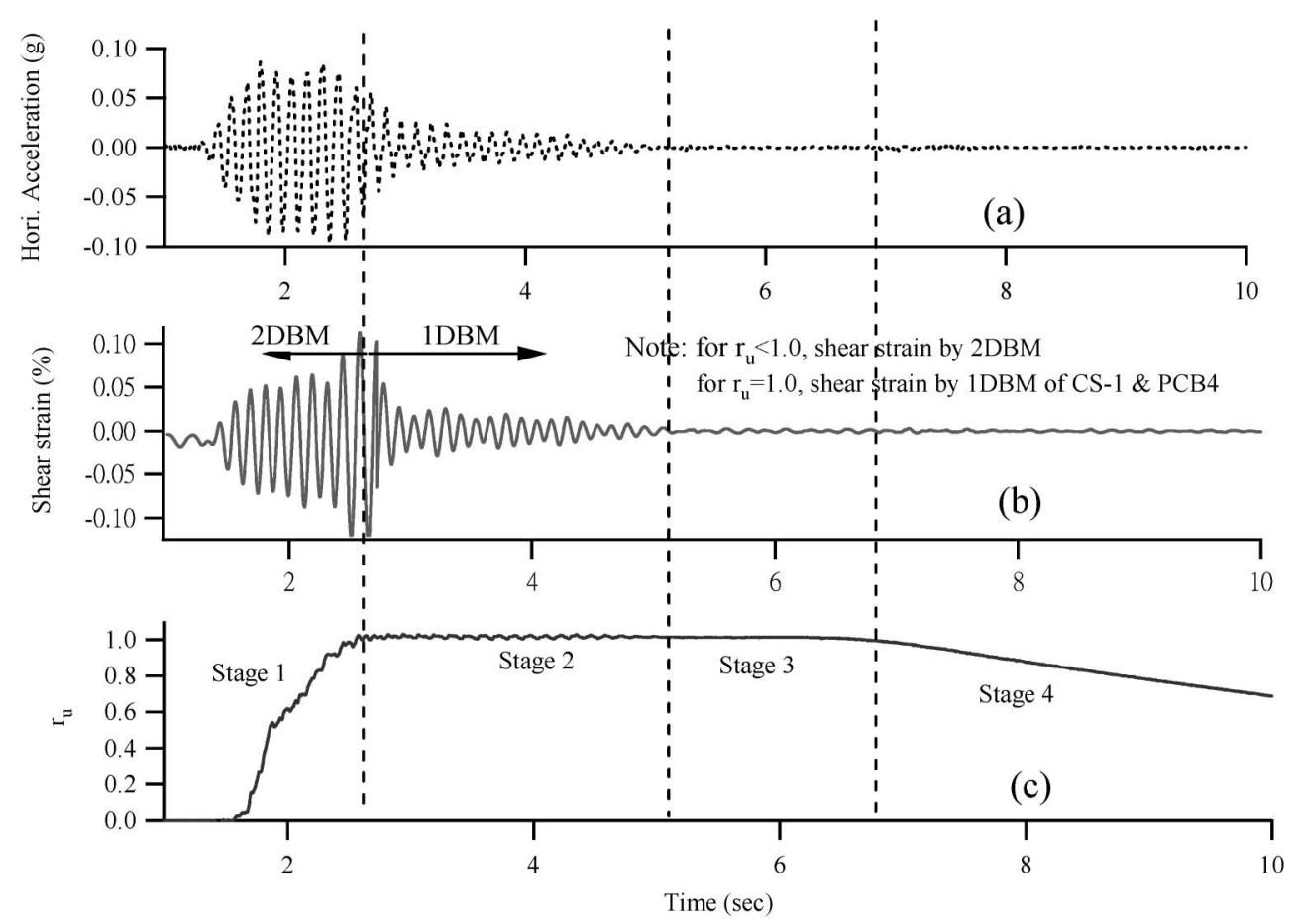

Fig. 7. Coupled response of soil liquefaction at coupled sensor CS-1: (a) horizontal acceleration, (b) shear strain and (c) excess pore pressure ratio 
cated that the ground motion had been altered. The soil maintained the liquefied state in stage 3 , which started when shaking ended and lasted to the end of liquefied state. In this stage, the liquefied state was solely attributed to the redistribution of excess pore pressure because no significant cyclic shearing occurred. It should be addressed that stage 3 only existed within certain liquefied depth. In cases with shallow liquefied zone, this stage was relatively short or not reached. The interval of stages 2 and 3 in Fig. 7 defines the duration of the soil in liquefied state. The final stage represented the dissipation of excess pore pressure.

\section{Spatial Coupled Response}

The spatial variations of coupled responses for the entire specimen were evaluated with the excess pore pressures measured at different depths and the shear strains evaluated at the corresponding depths. Because the number of internal instruments was not sufficient to evaluate shear strains at depths of all piezometers, shear strains by FSBM with relative displacements from adjacent frames corresponding to the elevations of those piezometers were used for shear strain evaluations. Since the shear strain by FSBM is more appropriate before the initial liquefaction occurred at the lower frame, the shear strain after liq- uefaction at the lower frame is plotted with dash line to address the discrepancy in rate of free vibration decay. The coupled shear strain-pore pressure responses within the liquefied zone are shown in Fig. 8 with the marked times of initial liquefaction (TI) and end of liquefied state (ELS) at the midpoint of measured depths.

According to the results shown in Fig. 8, three important characteristics of coupled shear strain-pore pressure responses have been observed. First, the shear strain amplitude increased as the pore pressure increased and the maximum shear strain at a specific depth was observed at the time of initial liquefaction then followed by decrements of strain amplitude in a free vibration fashion. The internal and frame responses shown in Fig. 5 could not find consistent characteristics in phase and amplitude to match the time of initial liquefaction. As a result, the maximum induced shear strain level is a better index in precisely defining the time of initial liquefaction than motion responses. Second, the initial liquefaction was first developed near the surface of soil deposit and the liquefied zone extended deeper as the shearing continued. The liquefied zone propagated downward very fast near the surface and slowed down in deeper zone. Third, the duration of soil in liquefied state decreased as the depth increased. The duration of liquefied state is an
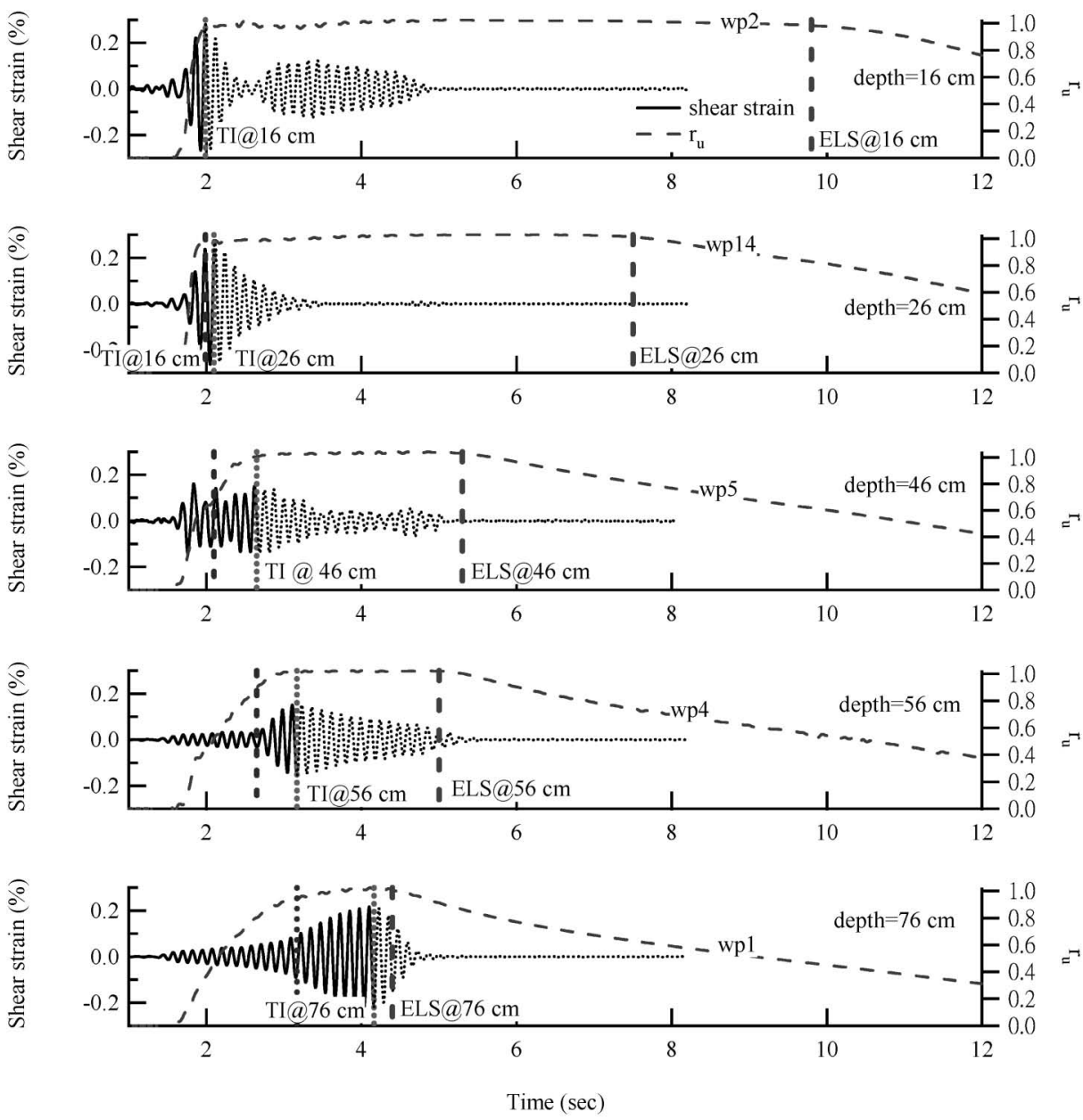

Fig. 8. Spatial variation of coupled responses within the liquefied zone 
important factor that affects the magnitude, depth, and area of lateral soil movement in a gently inclined soil stratum. The longer period of liquefaction state induced larger lateral deformation. Spatial variation of liquefaction duration could affect the distribution of permanent lateral displacement in liquefied layer and should be included in analytical flow models (e.g., Towhata et al., 1992) or numerical simulations for better predictions of permanent lateral displacements.

The temporal and spatial variations of coupled shear strain-pore pressure responses are essential but crucial for liquefaction studies on free fields as well as physical modelling of soil-structure interaction in liquefied soils. The results clearly show that the implemented shear strain evaluation techniques not only agree well with the pattern of pore pressure generation but also help in determining the time of initial liquefaction. These insights of coupled features are beneficial for verifying and interpreting testing data in various physical modelling of liquefaction studies.

\section{SUMMARY AND CONCLUSION}

This paper presents the implementations of improved techniques for evaluating coupled shear strain pore pressure responses of soil in shaking table tests. Dense internal and external instrumentations were deployed to provide data for study of temporal and spatial variations of soil responses during liquefaction process and to perform cross comparisons of different shear strain evaluation methods. Four coupled sensors, which integrate a 3-axis accelerometer and a miniature pore pressure transducer in a small case to eliminate the time lag of measuring the motions and pore pressures at a given location, were installed in a square instrumentation array.

Three strain evaluation methods, which use the specimen motions recorded from internal embedded sensors and/or the external frame motions, were utilized to evaluate shear strain-time histories in 1D horizontal shaking cases. In non-liquefied zone, shear strains calculated by measurements of internal and external sensors agreed well. Based on comparisons of shear strains from different measurements, three conclusions are drawn for cases with liquefied and non-liquefied zones: (1) alternating soil motion due to liquefaction could affect the results of strain evaluation, (2) data for displacement-based methods should be measured within the soil of the same phase, and (3) shear strain amplitude evaluated in FSBM with relative displacement of adjacent frames could be an alternative approximation of the local shear strain in the liquefied zone until the liquefied zone extended to the lower frame.
Spatial variations of coupled responses for the entire specimen are shown from shear strains evaluated by FSBM of adjacent frames and pore pressure measurements at corresponding depths. Characteristics of coupled shear strain-pore pressure responses were observed, which include the temporal variations of induced shear strain prior and after the initial liquefaction, development of liquefied zone, and duration of liquefaction state. This study also reveals that the maximum induced shear strain level is a better index in precisely defining the time of initial liquefaction than motion responses. The temporal and spatial variations of coupled shear strainpore pressure responses are crucial for liquefaction studies. Therefore, identification of these coupled features will be beneficial for verifying and interpreting testing data in physical modelling for liquefaction studies.

\section{ACKNOWLEDGEMENT}

This study was supported by the National Science Council, Taiwan, ROC, under grant No. NSC 94-2211-E-260-006, and by the National Center for Research on Earthquake Engineering in project NCREE94A06000-10. The authors would also like to express their sincere appreciations to the engineers at NCREE for their kind assistances in conducting the tests on the shaking table.

\section{REFERENCES}

1) Andrus, R. and Stokoe, K. (2000): Liquefaction resistance of soils from shear wave velocity, Journal of Geotechnical and Geoenvironmental Engineering, 126(11), 1015-1025.

2) Chang, W. (2002): Development of an in situ dynamic liquefaction test, PhD Dissertation, The University of Texas at Austin.

3) Chang, W. and Hong, M. (2008): Effects of clay content on liquefaction characteristics of gap-graded clayey sands, Soils and Foundations, 48(1), 101-114.

4) Dobry, R., Ladd, R., Yokel, F., Chung, R. and Powell, D. (1982): Prediction of Pore Water Pressure Build-up and Liquefaction of Sands During Earthquakes by the Cyclic Strain Method, National Bureau of Standards Building Science, Series 138.

5) Koga, Y. and Matsuo, O. (1990): Shaking table tests of embankments resting on liquefiable sandy ground, Soils and Foundations, 30(4), 162-174.

6) Rathje, E., Chang, W. and Stokoe, K. (2005): Development of an in situ dynamic liquefaction test, Geotechnical Testing Journal, ASTM, 28(1), 65-76.

7) Towhata, I., Sasaki, Y., Tokida, K., Matsumoto, H., Tamari, Y. and Yamada, K. (1992): Prediction of permanent displacement of liquefied ground by means of minimum energy principle, Soils and Foundations, 32(3), 97-116.

8) Ueng, T., Wang, M., Chen, M., Chen, C. and Peng, L. (2006): A large biaxial shear box for shaking table test on saturated sand, Geotechnical Testing Journal, ASTM, 29(1), 1-8. 